\title{
Analisis Geohazard untuk Dasar Laut dan Bawah Permukaan Bumi
}

\author{
Dani Urippan dan Eko Minarto \\ Departemen Fisika, Fakultas Ilmu Alam, Institut Teknologi Sepuluh Nopember (ITS) \\ e-mail:e.minarto@gmail.com
}

\begin{abstract}
Abstrak-Analisa geohazard pada permukaan dasar laut (Seabed) dan bawah permukaan bumi (Sub-seabed) merupakan upaya yang perlu dilakukan untuk mengetahui fitur-fitur dasar laut dan bawah permukaan bumi agar dampak dari geohazard dapat diminimalisir. Luas area penelitian $2 \times 4 \mathrm{~km}$, yang berada di perairan pulau Madura. Metode yang digunakan untuk menganalisa fitur bawah permukaan laut adalah metode Side Scan Sonar yang hasil pengolahannya akan di validasi dengan data Multibeam dengan menggunakan prinsip gelombang akustik yang menjalar ke dalam permukaan dasar laut sehingga didapatkan peta seabed feature. Sub Bottom profiler digunakan untuk menganalisa subseabed hingga kedalaman 40 m yang kemudian akan divalidasi dengan data seismik 2 dimensi untuk menganalisa fitur bawah permukaan hingga kedalaman $3 \mathrm{~km}$. Pesebaran kontur kedalaman memiliki water depth $42 \mathrm{~m}$. Pada line 8 terdapat patahan di kedalaman $971 \mathrm{~m}$. Jarak Jack-up footprint dengan lokasi pemboran $1207 \mathrm{~m}$ di sebelah timur lapangan DNI, memiliki diameter $25 \mathrm{~m}$ dan kedalaman 0.7 m. Pockmark yang terdekat dengan lapangan DNI sejauh 394 m sebelah utara timur laut. Kontur Kedalaman dari reflector 1 berada pada interval $5-7 \mathrm{~m}$ di bawah permukaan laut. Jarak shallow channel terdekat dengan lapangan DNI berada pada $65 \mathrm{~m}$ di sebelah selatan dengan kedalaman antara 10 hingga $6 \mathrm{~m}$. Jarak shallow anomaly terdekat terletak pada jarak $145 \mathrm{~m}$ di sebelah barat. Berdasarkan hasil tersebut kondisi pengajuan lokasi pengeboran dinyatakan aman dari bahaya geohazard.
\end{abstract}

Kata Kunci-Geohazard, Side Scan Sonar, Sub-bottom Profiler, Seismic, Seabed Feature.

\section{PENDAHULUAN}

$\mathrm{D}$ ALAM melakukan aktivitas eksplorasi maupun eksploitasi hidrokarbon terdapat kemungkinan terjadinya bencana geologi (Geohazards). Geohazard memiliki dampak secara langsung maupun tidak langsung. Seperti bahaya yang diakibatkan oleh gas pada lapisan dangkal, adanya patahan dekat permukaan pengeboran, gletser atau saluran (channel) sungai bawah permukaan, dan benda benda buatan manusia [1].

Terjadinya Geohazards telah memakan biaya ratusan juta dolar bagi industri minyak karena dapat menimbulkan kegagalan, kehilangan sirkulasi, dan ledakan gas dangkal (shallow blowouts). Salah satu tujuan utama dalam penelitian ini adalah untuk menilai geohazard dan mengetahui resiko yang ditimbulkan untuk operasi pengeboran di dasar laut dan kondisi geologi untuk dikelola dan dikurangi. Kehadiran hazard atau bahaya harus ditentukan melalui analisa yang baik dan konsisten serta jelas untuk dilaporkan dalam teks, peta, dan grafis lainnya [1].

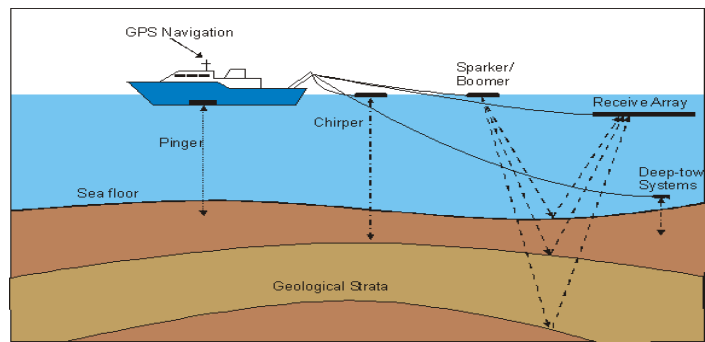

Gambar 1. Jenis-jenis alat metode Sub Bottom Profiler.

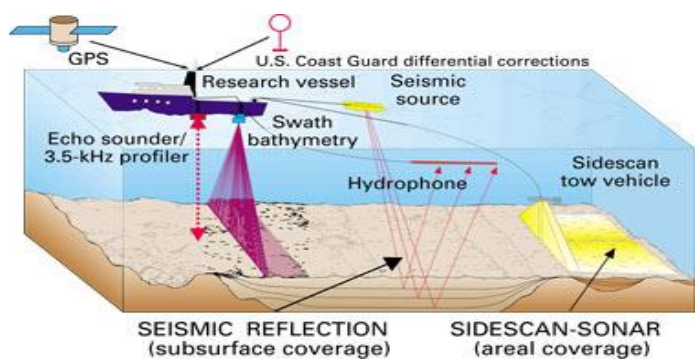

Gambar 2. Penempatan alat penelitian yang digunakan.

Metode Side Scan Sonar (SSS) mempunyai kemampuan menduplikasikan beam yang diarahkan pada satu sisi ke sisi lainnya, sehingga kita dapat melihat kedua sisi, memetakan semua area penelitian secara efektif dan menghemat waktu penelitian. SSS menggunakan narrow beam pada bidang horisontal untuk mendapatkan resolusi tinggi di sepanjang lintasan dasar laut. Instrumen ini mampu membedakan besar kecil partikel penyusun permukaan dasar laut seperti batuan, lumpur, pasir, kerikil, atau tipe-tipe dasar perairan lainnya. Gambar 1 merupakan jenis jenis alat metode Sub Bottom Profiler [2].

Untuk menganalisa bawah permukaan bumi digunakan dua metode yaitu: Metode Sub Bottom Profiler dan Metode Seismik, kedua metode tersebut menggunakakn prinsip gelombang akustik yang menjalar kedalam permukaan bumi [3]. Gelombang akustik memiliki dua jenis gelombang utama adalah gelombang body dan gelombang permukaan. Gelombang body menjalar melewati lapisan dalam bumi, tapi gelombang permukaan hanya dapat bergerak di permukaan bumi. Gempa menjalarkan energi seismik sebagai gelombang body dan gelombang permukaan [4]. Gambar 2 merupakan ilustrasi penempatan alat yang digunakan dalam penelitian ini. 


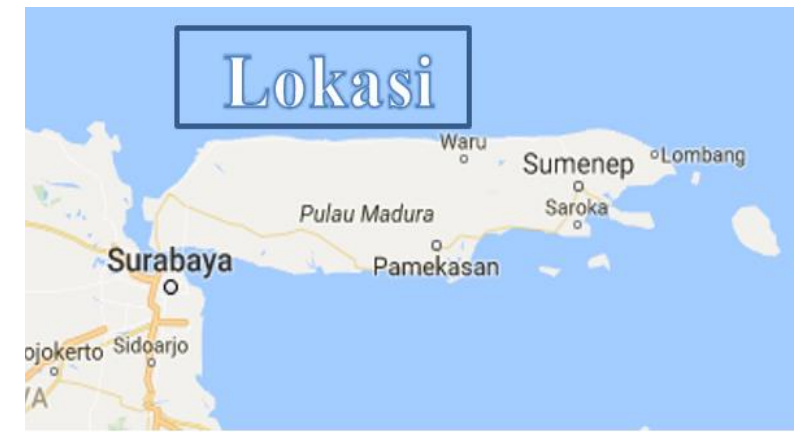

Gambar 3. Lokasi Penelitian.

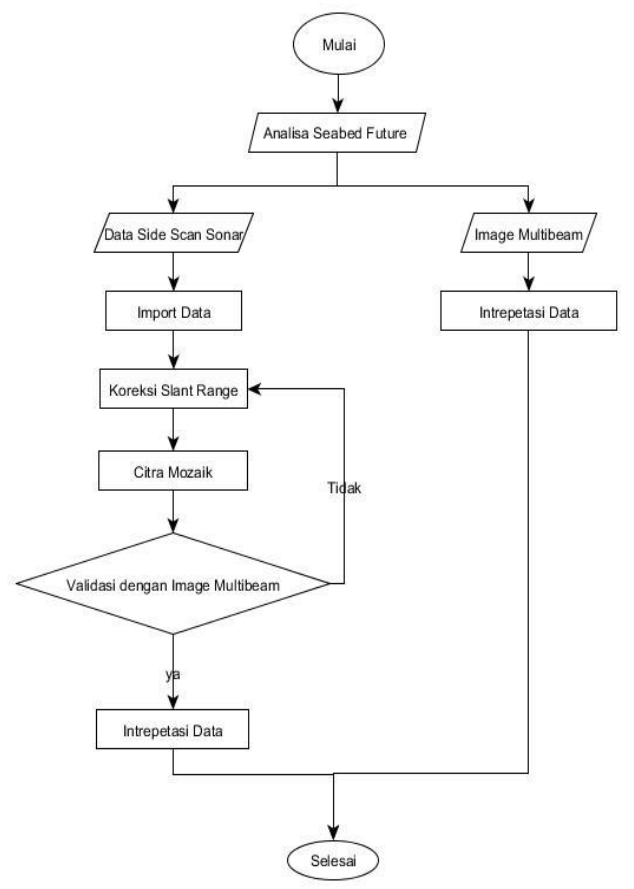

Gambar 5. Diagram alir analisa seabed future.

Pengukuran pada metode ini menggunakan waktu tempuh gelombang seismik pada saat terkirim dan diterima sebagai akibat dari pantulan dari bidang lapisan batuan yang mempunyai cepat rambat berbeda. Perbandingan perbedaan cepat rambat gelombang seismik pada dua media yang mengakibatkan gelombang seismik terpantul disebut koefisien refleksi. Metode tersebut memiliki perbedaannya terletak pada besar frekuensi yang digunakan. Besar kecilnya frekuensi yang digunakan akan berpengaruh pada penetrasi dan resolusi yang didapat. Sehingga akan didapatkan analisa geohazard yang lebih valid [5].

\section{URAIAN PENELITIAN}

\section{A. Daerah dan Waktu Penelitian}

Dalam penelitian ini digunakan data yang berada di perairan pulau Madura, Jawa Timur. Akan tetapi untuk koordinat lebih tepatnya merupakan rahasia perusahaan. Adapun peta lokasi penelitian ditunjukkan oleh Gambar 3.

Akuisisi dalam penelitian ini terdiri dari 44 line penelitian, line 1 hingga line 23 merupakan line horizontal sedangkan line 21 hingga line 44 merupakan line vertikal. Dalam penelitian ini jarak antar line pun berbeda-beda, dengan ukuran penelitian

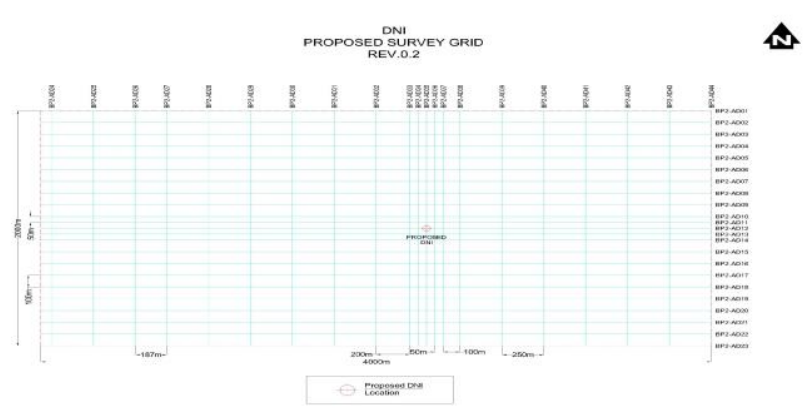

Gambar 4. Desain Penelitian.

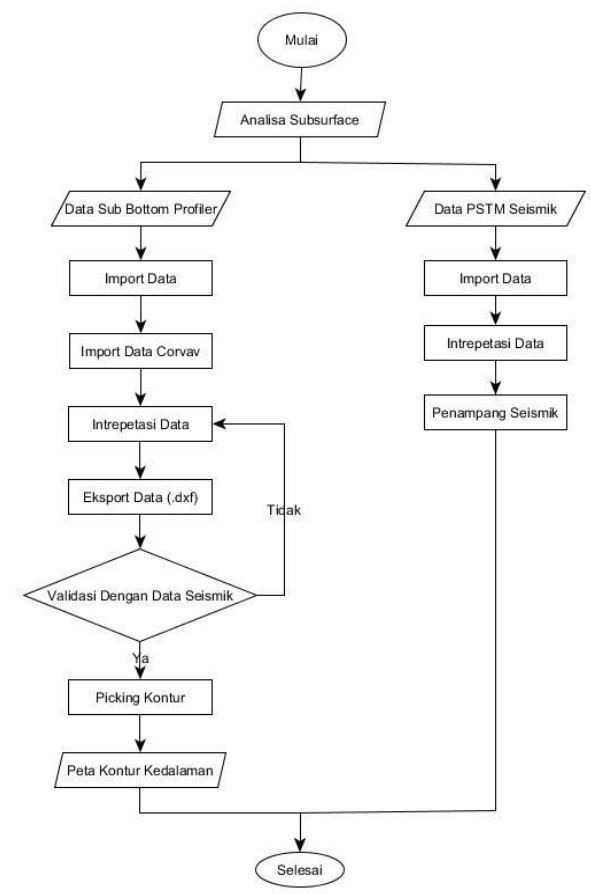

Gambar 6. Diagram alir analisa subseabed.

2000 meter kali 4000 meter. Analisa geohazard pada seabed dan sub-seabed ini difokuskan pada zona titik pemboran lapangan DNI yang terletak pada perpotongan line 12 dan line 35. Untuk lebih jelasnya akan di ditunjukan pada Gambar 4.

\section{B. Pengumpulan Data}

Dalam penelitian ini memiliki klasifikasi dua macam data, yang pertama data yang diolah dan di intrepetasikan dalam penelitian ini dan data validasi. Data yang di gunakan dalam penelitian ini adalah :

1. Data side scan sonar

2. Data multibeam (image)

3. Data sub bottom profiler

4. Data seismic $2 D$ (PSTM)

5. Data coring geotechnical

Dari data diatas akan diolah menggunakan software untuk processing dan intrepetation agar data yang didapat menjadi valid. Berikut merupakan software yang digunakan dalam penelitian ini.

1. AutoCAD 2007

2. Microsoft office 2013

3. Coda Outopus

4. Seisvision ke format PDF 


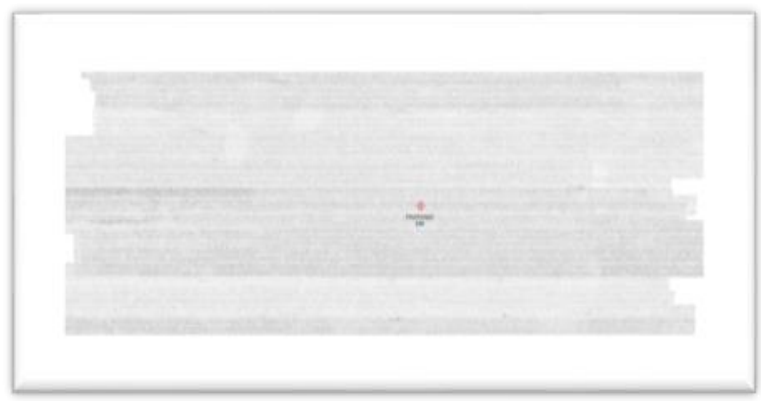

Gambar 7. Mozaik Side Scan Sonar.

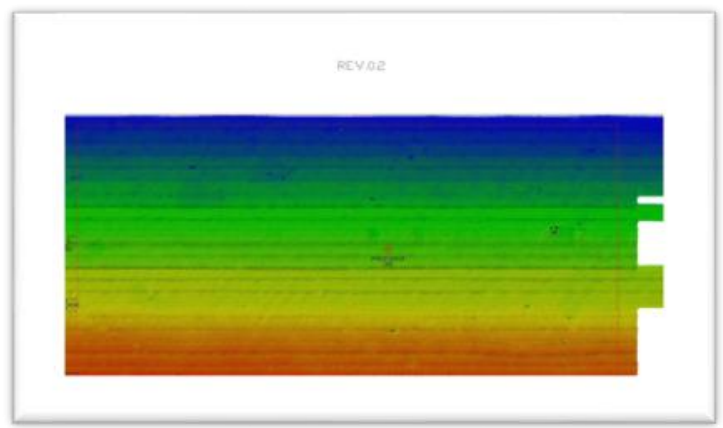

Gambar 8. Image Multibeam Echosounder.

\section{C.Tahapan Pengolahan Data}

Dalam penelitian ini memiliki dua tahapan pengolahan data yaitu data analisa seabed future dan data analisa subseabed. Kedua data tersebut yang akan menjadi acuan untuk memastikan bahwa dampak geohazard dapat diminimalisir. Adapun tahapan pengolahan data ditunjukan oleh Gambar 5 dan Gambar 6.

Dari diagram alir pada Gambar 5 terdapat dua garis besar pengolahan data analisa seabed

Dalam proses pengolahan data ini dibagi menjadi dua yaitu :

a. Pengolahan Side Scan Sonar

1. Import Data Side Scan Sonar kedalam software selanjutnya pastikan jumlah data yang dimasukan sesuai dengan jumlah data pada saat akuisisi. Serta masukan koreksi navigasi agar data yang di inputkan sesuai dengan letak posisi penelitian sesungguhnya.

2. Koreksi Slant Range merupakan koreksi jarak miring yang bertujuan untuk mengoreksi data yang memiliki garis putih di tengah jalur pengukuran data side scan. Serta dalam proses ini dilakukan pengontrolan terhadap Time Varied Gain agar gain yang digunakan baik untuk mengintrepetasikan data, pengaturan filtering data juga dilakaukan dalam proses ini.

3. Mozaik citra pada side scan sonar bertujuan untuk menggabungkan data yang side scan setiap line. Dalam proses ini dapat dilakukan penggabungan data sesuai kebutuhan, dapat dilakukan penggabungan data horizontal saja ataupun data vertikal dan juga dapat dilakukan penggabungan semua data.

4. Hasil pengolahan side scan sonar adalah sebuah peta batimetri yang nantinya digunakan untuk kebutuhan analisa seabed.

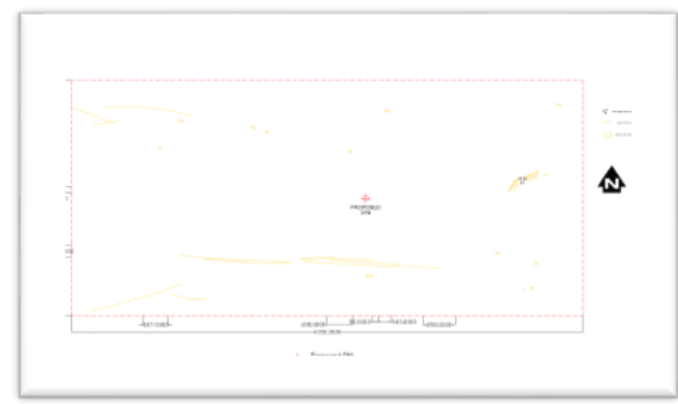

Gambar 9. Peta Seabed Features.

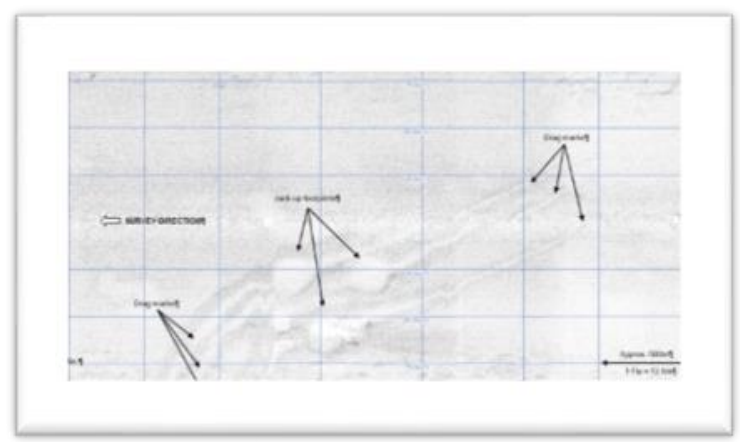

Gambar 10. Jack-up footprint data side scan sonar.

b. Pengolahan Image Multibeam Echosounder

1. Image multibeam bertujuan sebagai data pembanding pemetaan seabed. Dari image dapat dianalisa benda-benda yang terdapat pada pemukaan dasar laut (seabed).

2. Hasil dari image multibeam akan dijadikan data pembanding untuk membuat peta seabed features

Setelah didapatkan peta seabed features maka akan dilakukan pengolahan data untuk mendapatkan informasi bawah permukaan bumi (subseabed). Alur pengolahan data untuk menganalisa subseabed ditunjukkan oleh Gambar 6.

Dalam proses pengolahan data untuk menganalisa subseabed dibagi menjadi dua tahap sesuai dengan metode yang digunakan sebagai berikut :

a. Pengolahan data Sub Bottom Profiler

1. Import data Sub bottom profiler ke dalam software Coda. Pastikan jumlah data yang di inputkan sama dengan jumlah lintasan akuisisi data.

2. Import data cornav merupakan proses penginputan data posisi letak pengukuran. Proses ini sangat penting untuk memastikan bahwa data yang diinputkan sudah dalam koordinat sebenarnya. Dalam proses ini juga akan di atur nilai $T V G$ agar gain yang digunakan dapat memudahkan dalam proses intrepetasi

3. Intrepetasi data sub bottom profiler merupakan proses pembacaan data diantaranya menentukan posisi lapisan reflector dan keberadaan shallow channel serta menentukan shallow anomaly yang berada di subseabed.

4. Eksport data kedalam format (.dxf) bertujuan untuk mengolah data $S B P$ kedalam program AutoCad untuk memetakan data yang sudah diolah

5. Dilakukan proses validasi data yang ada di $S B P$ dengan data seismik sehingga data yang didapatkan lebih akurat. 


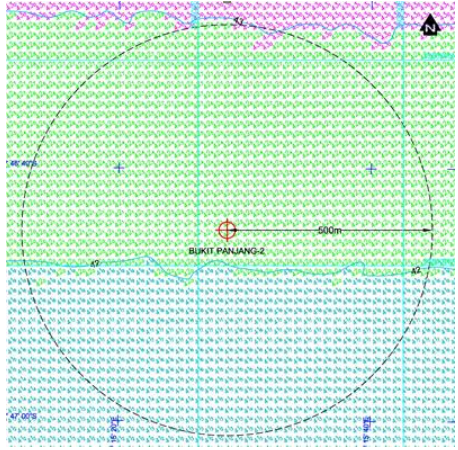

Gambar 11. Data kedalaman laut dengan menggunakan data Multibeam.

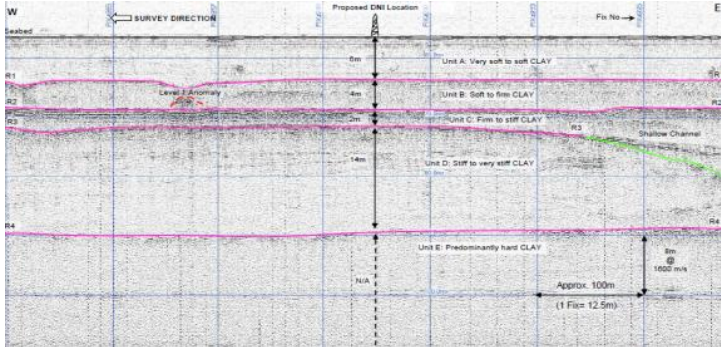

Gambar 12. Data Sub bottom profiler line 12.

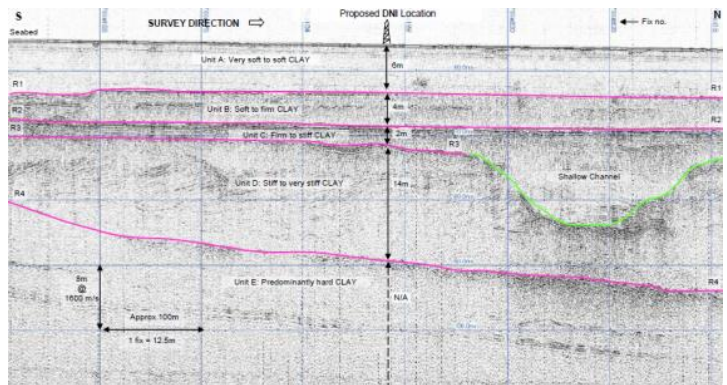

Gambar 13. Data Sub bottom profiler line 35.

b. Pengolahan data Post Stack Seismik

1. Import data dalam bentuk SEG-Y kedalam software Seisvision, dan pastikan juga mengimport data navigasi agar data yang di intrepetasi sudah berada dalam korrdinat yang sesungguhnya.

2. Intrepetasi data seismik dilakukan dengan cara melakukan picking horizon yang akan memberikan informasi beda lapisan melalui informasi velocity analysis. Serta dilakukan picking fault agar mengetahui dimana posisi patahannya.

3. Dihasilkan penampang seismik yang akan di jadikan landasan keamanan dalam pengeboran.

Setelah dilakukan analisa seabed dan analisa subseabed maka akan dilakukan pembuatan laporan penelitian, sehingga dapat di hasilkan analis y yang runtut dan valid.

\section{HASIL DAN PEMBAHASAN}

\section{A. Analisa Seabed Features}

Analisa seabed features merupakan analisa pada dasar permukaan laut. Analisa ini dapat dilakukan menggunakan data yang di peroleh dari side scan sonar dan multibeam. Side scan sonar merupakan metode pencitraan bawah air yang menggunakan prinsip gelombang akustik yang terpancar. Alat ini ditarik di belakang kapal (towfish). Sinyal akustik yang di

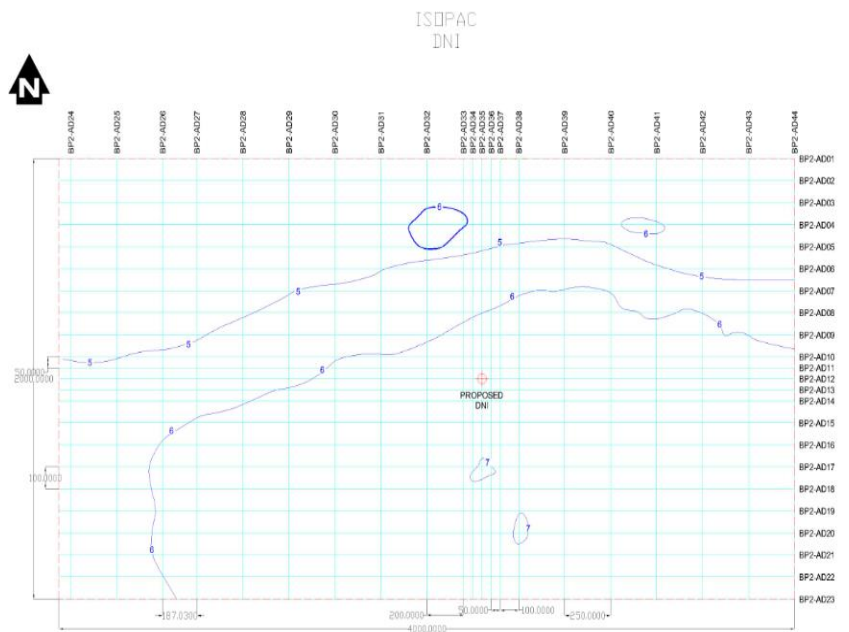

Gambar 14. Peta Isopac.

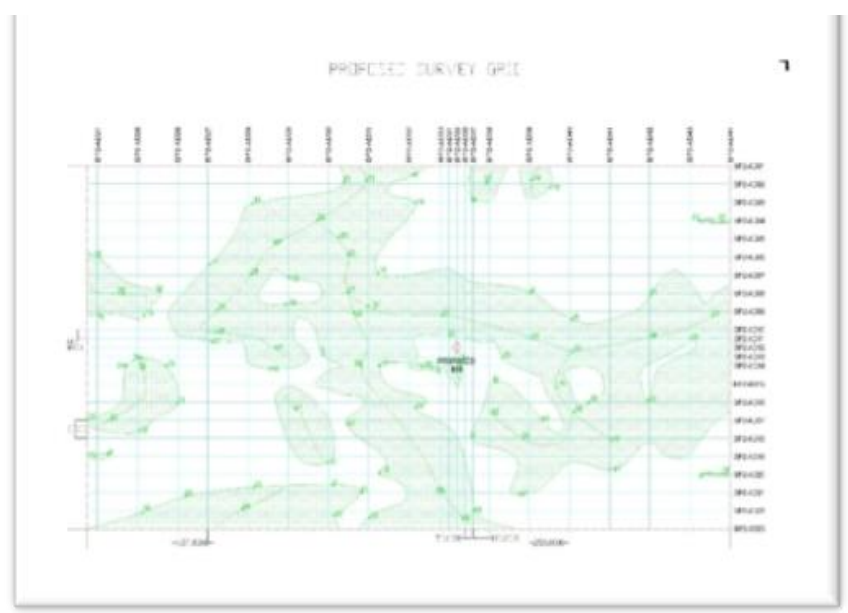

Gambar 15. Pesebaran Shallow Channel.

kirim dari transducer akan merubah gelombang akustik menjadi energi mekanik yang menuju dasar permukaan laut. Sinyal tersebut akan terhambur dan terabsorbsi serta terefleksi kembali ke sonar fish yang di tangkap receiver. Alat yang digunakan pada penelitian ini mempunyai frekuensi antara 120 kHz-600 kHz yang mampu menjangkau jarak sisi kapal antara 100 meter hingga 230 meter. Nilai resolusi yang di dapatpun berbeda-beda. Semakin dalam data yang di dapat maka resolusi yang didapat pun akan berkurang.

Pada penelitian ini dilakukan akuisisi pengambilan data sebanyak 44 line, yang terbagi menjadi 23 line horizontal dan 21 line vertical, data side scan sonar harus dilakukan koreksi navigasi yang bertujuan untuk memastikan koordinat pengukuran sudah tepat. Selanjutnya dilakukan koreksi garis miring atau slant range, koreksi ini bertujuan untuk menggabungkan data yang terpotong karena garis putih di tengah jalur pengukuran side scan sonar, agar Gambar yang dihasilkan lebih halus dapat di atur dengan menggunakan TVG (time varied gain) atau menggukan filtering frekuensi. selanjutnya dilakukan pembuatan citra mozaik, yaitu untuk menggabungkan semua data perline menjadi satu data yang ditunjukkan oleh Gambar 7. Selanjutnya di export kedalam format (.geotiff) agar koordinat data tersebut tidak berubah. 


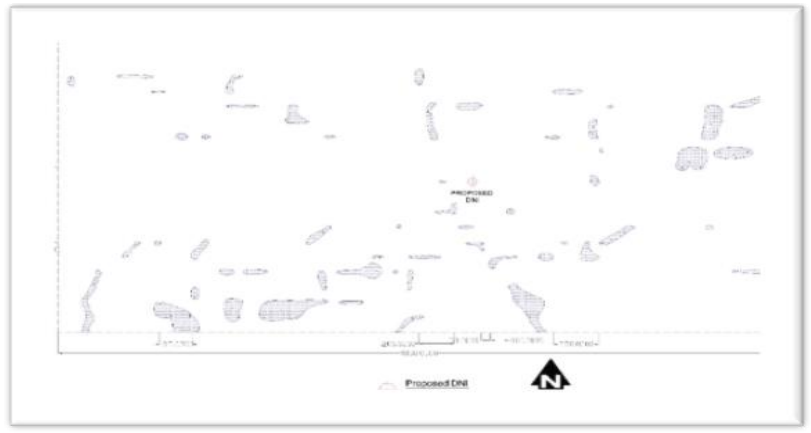

Gambar 16. Pesebaran Shallow Anomaly.

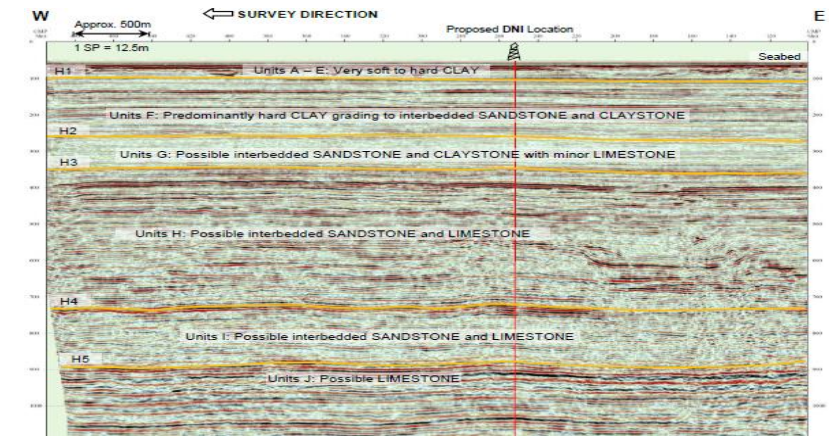

Gambar 17. Data seismik line 12.

Hasil citra mozaik dari side scan sonar nantinya akan di validasi dengan image Multibeam Echosounder agar di dapatkan hasil peta seabed features yang valid. Data multibeam dapat ditunjukkan oleh Gambar 8.

Dari data multibeam akan dibuat peta seabed features yang nantinya peta ini akan mempresentasikan keadaan bawah permukaan laut. Gambar 9 merupakan data yang sudah di plot menggunakan software AutoCad untuk memperjelas letak posisi anomaly yang berada di dasar permukaan laut.

Dari Gambar 10 dapat dilihat anomaly yang berada di bawah permukaan laut dari data side scan sonar. Terdapat Jarak Jackup footprint dengan lokasi pemboran sekitar 1207 meter sebelah timur lapangan DNI dengan diameter 25 meter dan memiliki kedalaman 0.7 meter. Pockmark yang terdekat dengan lapangan DNI sejauh 394 meter sebelah utara timur laut serta adanya bekas Scars Trawl.

Dari Gambar 11 dapat diketahui bahwa nilai water depth di lapangan DNI adalah 42 meter. Pesebaran kedalaman air laut dari data tersebut berkis ar antara 41 meter hingga 43 meter.

\section{B. Analisa Subseabed}

Urutan Analisa Subseabed merupakan analisa bawah permukaan lapisan bumi, yang dapat digunakan untuk analisa zona geologi. terdapat dua zona litologi yaitu zona litologi dangkal yang dapat di jelaskan melalui data sub bottom profiler dan zona litologi dalam yang dapat di analisa melalui data seismik.

Pada penelitian ini digunakan metode sub bottbom profiler yang berjenis pinger, alat ini memiliki frekuensi berkis ar antara 1.5-1.8 Khz yang memiliki penetrasi kedalaman mulai 10 meter hingga 40 meter. Alat ini memiliki domain waktu Two Way Time atau TWT yang diasumsikan kecepatan gelombang akustik pada lapisan sedimen bawah laut sebesar $1600 \mathrm{~m} / \mathrm{s}$.

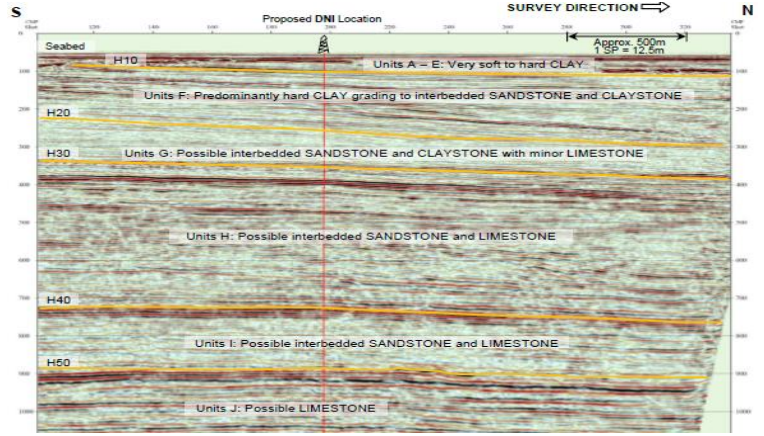

Gambar 18. Data seismik line 35.

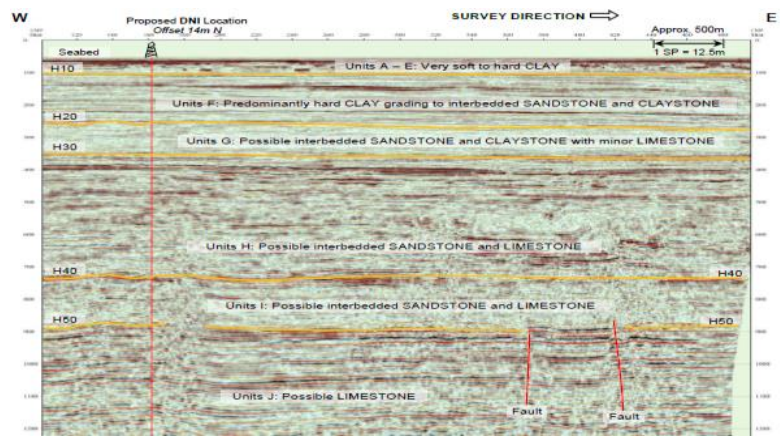

Gambar 19. patahan pada lintasan 8 .

Analisa yang pertama dilakukan pada tahap ini adalah analisa littologi pada lapisan dangkal. Data sub bottom profiler harus terlebih dahulu diatur frekuensi yang digunakan dengan menggunakan band pass filter atau dengan time varied gain yang bertujuan memperhalus data yang didapat agar lebih mudah di intrepetasikan. Gambar 4.10 dan Gambar 4.11 merupakan data sub bottom profiler. Data tersebut merupakan data dari titik lapangan yang akan dilakukan pengeboran. Line 12 merupakan data dari lintasan line vertikal dan line 35 merupakan data dari line horizontal. Data tersebut merupakan data yang sudah diintrepetasikan mulai dari lapisan seabed, reflektor pertama, reflektror kedua reflektor ketiga, reflektor keempat, shallow channel dan shallow anomaly. Dari data di atas dapat diketahui bahwa nilai water depth di lapangan DNI adalah 42 meter. Berikut merupakan hasil dari pembuatan peta isopac (lapis an reflector pertama).

Dari Gambar 14 dapat dilihat pesebaran kedalaman reflector pertama pada penelitian ini berkisar antara 5 meter hingga 7 meter. Dan nilai kedalaman reflektor pertama pada lapangan DNI adalah 6 meter. Selanjutnya akan dilakukan proses picking (tag) shallow channel. shallow channel sendiri merupakan sungai bawah laut yang terjadi karena pengendapan oleh sedimen yang terjadi ribuan tahun dan menjadi salah satu bencana bagi industri konstruksi lepas pantai karena adanya perbedaan lapisan pengisi atau sedimen terhadap sedimen di atasnya. Analisa ini sangat penting karena bangunan lepas pantai berdiri diatas lapisan yang tepat.

Dari Gambar 15 didapatkan pesebaran shallow channel yang terdapat pada penelitian ini. Terdapat banyak sekali channel pada bawah permukaan lapisan laut. Namun pada daerah lapangan DNI tidak terdapat shllow channel dan jarak shallow channel terdekat berada pada 50 meter di sebelah utara dengan kedalaman 13 meter sampai 31 meter. Ada yang berjarak 66 
meter selatan dari lapangan pemboran dengan kedalaman 10 meter hingga 16 meter, 167 meter sebelah barat dengan kedalaman 15 hingga 22 meter dan 300 meter tengara lapangan pemboran dengan kedalaman 12 hinnga 35 meter. Selanjutnya akan di picking shallow anomaly yang memiliki tujuan untuk memetakan pesebaran anomaly yang ada di daerah penelitian. Berikut merupakan petas pesebarannya. Gambar 15 merupakan ilustrasi pesebaran shallow channel yang diperbesar.

Shallow anomaly sendiri dampat menyebabkan bahaya geohazard, dari data di atas dapat di lihat bahwa keberadaan shallow anomaly pada daerah lapangan DNI relatif cukup aman, shallow anomaly terdekat terlepak pada jarak 125 meter barat daerah pemboran dengan kedalaman 9 meter, 145 meter di sebelah barat daya dengan kedalaman antara 8 hingga 9 meter yang ditunjukkan oleh Gambar 16.

Gambar 4.17 dan Gambar 4.18 merupakan data seismik pada lapangan DNI yang terletak pada line 12 dan line 35. Dari Gambar tersebut dapat dilihat tidak adanya anomaly yang membahayakan saat dilakukannya proses pengeboran.

Dari data seismik tersebut dilihat bahwa untuk mengintrepetasikan data pada waktu 200 detik tidak terlalu jelas. Maka dari itu di butuhkan data sub bottom profiler, sedangkan data seismik di gunakan untuk mengetahui lapisan bumi pada watu 100 detik keatas. Dari Gambar 19 terdapat adanya patahan yang terletak pada lintasan 8 pada waktu 880 ms TWT atau pada kedalaman 971 meter (Base on Sea Level).

\section{KESIMPULAN}

Berdasarkan penelitian yang telah dilakukan dapat dis impulkan:
1. Nilai water depth pada lapangan DNI sebes ar 42 meter.

2. Jarak Jack-up footprint dengan lokasi pemboran 1207 meter sebelah timur lapangan DNI dengan diameter 25 meter dan memiliki kedalaman 0.7 meter. Pockmark yang terdekat dengan lapangan DNI sejauh 423 meter sebelah barat serta adanya bekas penggalian pipa.

3. Kontur Kedalaman (Isopac) dari reflector 1 berada pada interval 5- $7 \mathrm{~m}$ di bawah permukaan laut.

4. Jarak shallow channel terdekat dengan lapangan DNI berada pada 50 meter di sebelah utara dengan kedalaman antara 13 hingga 31 meter.

5. Jarak shallow anomaly terdekat terlepak pada jarak 125 meter di sebelah barat dengan kedalamn 9 meter

6. Terdapat patahan di line 8 pada kedalaman 971 meter

7. Lokasi pemboran lapangan DNI dinyatakan memiliki dampat geohazard yang rendah.

\section{DAFTAR PUSTAKA}

[1] N. Azuan, Introdction to Geohazards. Jakarta: Java Offhore, 2015.

[2] R. Hidayaturrahman, "Peran Survei Hidrografi Dalam Kegiatan Pemantauan Pipa Di Dasar Laut," Bandung, 2014.

[3] A. Berkhout and D. . Wulfften, "Migration in the Presence of Noise," Geophys. Prospect., vol. 28, no. 3, pp. 372-383, 1980.

[4] A. Hilyah, "Studi Gempa Mikro untuk mendeteksi Rekahan di area Panas bumi Kamojang Kabupaten Garut," J. Fis. dan Apl., vol. 6 , no. 2,2010 .

[5] R. Holmes, "The Issue Surrounding A Shallow Gas Database In A Relation To Offshore Hazard," Edinburgh, 1997. 